\title{
Targeting Btk/Etk of prostate cancer cells by a novel dual inhibitor
}

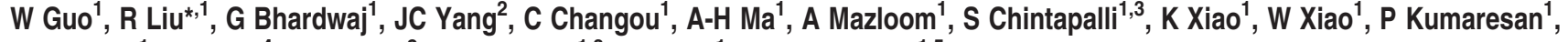 \\ E Sanchez ${ }^{1}$, C-T Yeh ${ }^{4}$, CP Evans ${ }^{2}$, R Patterson ${ }^{1,3}$, KS Lam $^{1}$ and H-J Kung ${ }^{* 1,5}$
}

Btk and Etk/BMX are Tec-family non-receptor tyrosine kinases. Btk has previously been reported to be expressed primarily in B cells and has an important role in immune responses and B-cell malignancies. Etk has been shown previously to provide a strong survival and metastasis signal in human prostate cancer cells, and to confer androgen independence and drug resistance. While the role of Etk in prostate carcinogenesis is well established, the functions of Btk in prostate cancer have never been investigated, likely due to the perception that Btk is a hematopoietic, but not epithelial, kinase. Herein, we found that Btk is overexpressed in prostate cancer tissues and prostate cancer cells. The level of Btk in prostate cancer tissues correlates with cancer grades. Knockdown of Btk expression selectively inhibits the growth of prostate cancer cells, but not that of the normal prostate epithelial cells, which express very little Btk. Dual inhibition of Btk and Etk has an additive inhibitory effect on prostate cancer cell growth. To explore Btk and Etk as targets for prostate cancer, we developed a small molecule dual inhibitor of Btk and Etk, CTN06. Treatment of PC3 and other prostate cancer cells, but not immortalized prostate epithelial cells with CTN06 resulted in effective cell killing, accompanied by the attenuation of Btk/Etk signals. The killing effect of CTN06 is more potent than that of commonly used inhibitors against Src, Raf/VEGFR and EGFR. CTN06 induces apoptosis as well as autophagy in human prostate cancer cells, and is a chemo-sensitizer for docetaxel (DTX), a standard of care for metastatic prostate cancer patients. CTN06 also impeded the migration of human prostate cancer cells based on a 'wound healing' assay. The anti-cancer effect of CTN06 was further validated in vivo in a PC3 xenograft mouse model.

Cell Death and Disease (2014) 5, e1409; doi:10.1038/cddis.2014.343; published online 4 September 2014

Prostate cancer is the most frequently diagnosed cancer and the second leading cause of cancer deaths in men in the United States. ${ }^{1}$ The risk and side effects associated with current therapies, which range from impotence and incontinence after surgery to recurrence of an androgen-independent tumor after androgen ablation therapy, are severe. Tyrosine kinase inhibitors (TKIs) are among the most promising targeted therapies, most of which are directed against receptor tyrosine kinases. The outcomes of clinical trials based on TKIs as single agents have generally been modest, probably due to redundancy in receptor binding and signaling to intracellular mediators. ${ }^{2}$

The Tec family of tyrosine kinases is the second largest family of cytoplasmic tyrosine kinases. It consists of six members with tissue-specific expression patterns in normal cells. Btk is the prototype of this family of tyrosine kinases. Btk is reportedly expressed primarily in B cells, monocytes, macrophages and neutrophils, ${ }^{3}$ as well as in B-cell malignancies. In addition to being a critical effector for the B-cell receptor, ${ }^{4}$ Btk engages B-cell Toll-like receptors (e.g., TLR2 and TLR4) ${ }^{5,6}$ and FAS. $^{3}$ Btk is activated by SFK (src family kinases) and Syk, and transmits signals to PI3K and PLCgamma, resulting in a calcium flux and the activation of NF-kB and NFATc transcriptional factors. ${ }^{7,8}$ The role of Btk in the immune response and hematopoietic malignancies has been well studied. Deficiency of Btk in humans leads to X-linked agammaglobulinemia (XLA). ${ }^{4}$ Btk has been reported as an anti-apoptotic protein in neutrophils and macrophages. Btkdeficient neutrophils have increased production of ROS and stimulation-induced apoptosis. ${ }^{3}$ Knockdown of Btk in macrophages led to increased LPS and TNF-induced apoptosis. ${ }^{6}$ Btk also has an important role in arthritis, leukemia and lymphoma. Several Btk inhibitors have been reported including LFM-A13, a reversible Btk inhibitor through rational design, ${ }^{9}$ and $\mathrm{PCl} 32765$, an irreversible Btk inhibitor. PCl32765 has shown encouraging effect in clinical studies for treatment of chronic lymphocytic leukemia and in collageninduced arthritis mouse model. ${ }^{10-12}$ These inhibitors also

\footnotetext{
${ }^{1}$ Department of Biochemistry and Molecular Medicine, University of California Davis, Sacramento, CA 95817, USA; ${ }^{2}$ Department of Urology, University of California Davis, Sacramento, CA 95817, USA; ${ }^{3}$ Department of Physiology and Membrane Biology, University of California Davis, Sacramento, CA 95817, USA; ${ }^{4}$ Department of Medical Research and Education, Taipei Medical University-Shuang Ho Hospital, Taipei, Taiwan, ROC and ${ }^{5}$ nstitute of Molecular and Genomic Medicine, National Health Research Institutes (NHRI), Miaoli County 35053, Taiwan, ROC.

*Corresponding authors: R Liu, Department of Biochemistry and Molecular Medicine, University of California Davis, 2700 Stockton Boulevard, Suite 2301, Sacramento, CA 95817, USA. Tel: +916 734 6414; Fax: +916 734 6415; E-mail: rwliu@ucdavis.edu

or H-J Kung, Department of Biochemistry and Molecular Medicine, UC Davis Cancer Center, 4645 2nd Avenue, Research III, Rm 2400D, Sacramento, CA 95817, USA. Tel: +916 734 1538; Fax: +916 734 2589; E-mail: hkung@ ucdavis.edu or Institute of Molecular and Genomic Medicine, National Health Research Institutes (NHRI), No. 35, Keyan Road, Zhunan Town, Miaoli County 35053, Taiwan, ROC. Tel: +886 37246166 ext. 31000; Fax: +886 37586402 ; E-mail: hkung@nhri.org.tw Abbreviations: CTN06, N-(7-isobutyl-6-oxo-1-(3-(piperidin-1-yl)propyl)-5,6-dihydro-1H-imidazo[4,5-g]quinoxalin-2-yl)-4-(pyridin-4-yl)benzamide; Btk, Bruton's tyrosine kinase; Etk, Endothelial and epithelial tyrosine kinase; XLA, X-linked agammaglobinemia; TKIs, tyrosine kinase inhibitors; CLL, chronic lymphocytic leukemia; SFK, Src family kinases; $C Q$, chloroquine; DTX, docetaxel; $\mathrm{PBTK}$, phospho-Btk

Received 08.4.13; revised 22.6.14; accepted 13.7.14; Edited by G Ciliberto
} 
exhibited potential in targeting multiple myeloma in the bone marrow microenvironment. ${ }^{13}$ Although these inhibitors greatly broadened the scope for potential Btk targeting in human diseases, reactivity of irreversible inhibitor with other proteins remains a concern. As a result, the development of a potent, reversible Btk inhibitor is highly desirable.

As described above, most reported studies of Btk focused on the hematopoietic system; however, the role of Btk in solid tumors remains unknown. By contrast, Etk (also called BMX), another member of Tec family, has been shown to be expressed in epithelial and endothelial cells, and is involved in the development or treatment resistance of several epithelial malignancies. ${ }^{14-16}$ It is overexpressed in human prostate cancer specimens, and provides strong survival functions in prostate cancer cells. ${ }^{17,18}$ Overexpression of Etk induces prostate intraepithelial neoplasia in mice, ${ }^{19}$ and knockout of Etk in an endothelial lineage decreases tumor angiogenesis and growth. ${ }^{20}$ We showed previously that Etk forms a complex with Src and FAK, and that it is an effective activator of STAT3 ${ }^{21,22}$ In prostate cancer cells, it is activated by EGFR and erbB3, ${ }^{23}$ as well as IL- 6 and neuropeptides, leading to aberrant activation of androgen receptor. ${ }^{24}$ Etk sequesters p53 and confers survival and therapeutic resistance. ${ }^{25}$ In glioblastoma, Etk was found to be critical in maintaining the self-renewal and tumorigenic potential of cancer stem cells through Stat3 activation. ${ }^{26}$ Therefore, systemic inhibition of Etk may offer a synergistic anti-tumor effect. As of yet, there is no efficacious inhibitor for this kinase.

Herein, we report that Btk is also aberrantly expressed in prostate cancer. Moreover, a novel Btk and Etk dual inhibitor, CTN06, was identified. CTN06 induces autophagy and apoptosis in prostate cancer cells, and inhibits prostate cancer xenograft tumor growth in vivo. To our knowledge, this is the first report of the role of Btk in solid tumors, and also the first report of a novel Btk/Etk dual inhibitor with an application as an anti-cancer agent.

\section{Results}

Btk is expressed at high levels in prostate cancer. Etk has previously been reported to be overexpressed in prostate cancer, and it promotes growth, survival and angiogenesis of prostate cancer. ${ }^{19,27}$ Btk, the closest member of Etk in the human kinome, was mainly reported in hematopoietic cells and B-cell malignancies. The role of Btk in solid cancers remains unknown. Using a tissue microarray assay, we found that Btk is overexpressed in prostate cancer tissues. Significantly, the expression level
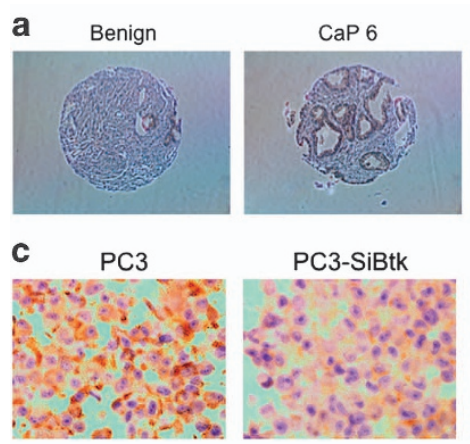

PC3-SiBtk

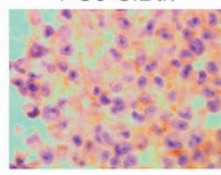

d

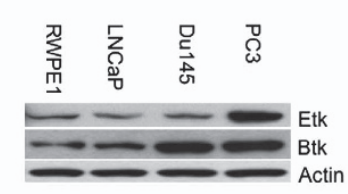

e

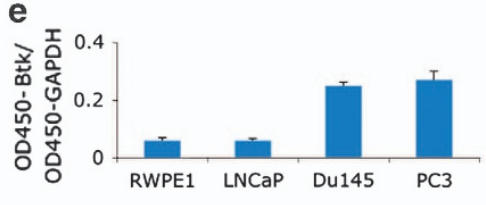

g

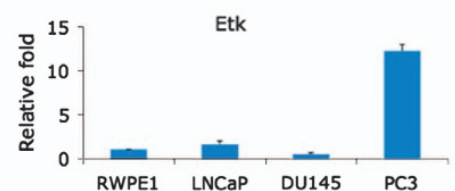

b
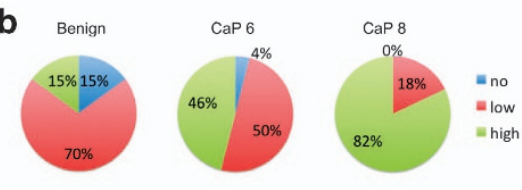

\begin{tabular}{c|c}
\hline Category & Samples \\
\hline Benign (BPH) & 28 \\
\hline Cap 6 (Gleason 6 CaP) & 48 \\
\hline Cap 8 (Gleason 8 CaP) & 46 \\
\hline
\end{tabular}

f

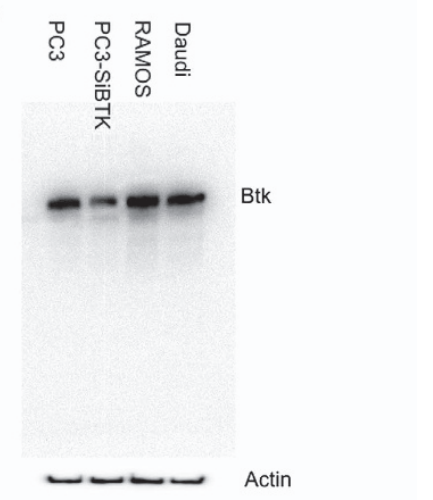

Btk

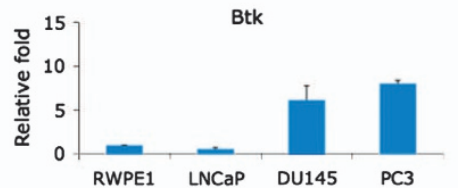

Figure 1 BTK is expressed in prostate cancers and cell lines. (a) The expression level of Btk in prostate cancer tissue was examined using tissue microarray. (b) The array contains 28 benign, 48 gleason $6(\mathrm{CaP} 6)$ and 46 gleason 8 (CaP 8) prostate cancer samples. (c) The antibody used was confirmed using cellblocks with PC3, PC3 with depletion of Btk by SiBtk and RAMOS cells. (d) The expression level of Etk and Btk in prostate cancer cells was examined using western blot assay. (e) Btk levels in prostate cancer cells were also measured using ELISA. (f) The antibody for tissue microarray was also confirmed using western blot with RAMOS cells and siBtk for PC3 cells, and with Daudi cells as a positive control. (g) Btk levels were further confirmed using RT-PCR. Columns, mean; bars, standard deviation, $n=3$ 
of Btk correlates with the grade of prostate cancer (Figures $1 \mathrm{a}$ and b). The antibody used for tissue microarray was confirmed using cell blocks with RAMOS cells as a positive control (Figure 1c). In addition to the tissue microarray, the expression level of Etk and Btk in prostate cancer cells LNCaP, Du145, PC3 and immortalized normal prostate cell RWPE1 was examined using western blots. Etk was found to be high in PC3 cells, and Btk was found to be high in both Du145 and PC3 cells, a similar expression pattern compared with the tissue microarray (Figure 1d). Btk levels in RWPE1, LNCaP, Du145 and PC3 cells were further measured using ELISA (Figure 1e). The specificity of the Btk antibody used was validated by the decreased Btk level, when Btk was knocked down by siRNA targeting Btk in PC3 cells, as well as in RAMOS cells which served as a positive control (Figure 1f). The elevated mRNA levels of Etk and Btk in those cells were also observed, using real-time RT-PCR, which indicates the overexpression of Etk and Btk in prostate cancer cells is at least in part at the transcriptional level (Figure 1g).

Simultaneous knockdown of Etk and Btk inhibits prostate cancer cell growth. Etk knockdown has been reported to slow down prostate cancer cell growth. A similar result was observed in $\mathrm{PC} 3$ cells with Etk knockdown (Figure 2a). To explore the role of Btk in prostate cancer cell growth, the Btk level in PC3 prostate cancer cells was knocked down using siRNA. Btk knockdown in PC3 cells showed a similar inhibitory effect on prostate cancer cell growth as compared with Etk knockdown. Simultaneous knockdown of Etk and Btk resulted in a much greater inhibitory effect on prostate cancer cell growth when compared with Etk or Btk knockdown alone (Figure 2a). In stark contrast, RWPE1, the immortalized normal prostate cell line, is resistant to Etk and Btk knockdown (Figure 2b), indicating an Etk/Btk 'addiction' of the prostate cancer cells. The effect of Btk to prostate cancer cell growth was further examined in PC3 cells and Du145 cells using SiBtk and LFMA13, a known Btk inhibitor. Both approaches inhibited prostate cancer cell growth at a similar level, further confirming an important role of Btk in prostate cancer cell growth (Figure 2c).

CTN06 as a dual inhibitor against Btk and Etk tyrosine kinases. Having identified a tumor-specific role of Btk and Etk in prostate cancer, we attempted to develop inhibitors targeting this family of kinases. Through screening a 9600diversity combinatorial solution phase small molecule library, hit compounds with inhibitory activities against Etk were discovered. Subsequent optimization led to the identification of CTN06 (Figure 3a). To determine the substrate specificity of this compound, purified Etk, Btk, Src and Mer were incubated in a kinase reaction buffer with CTN06 $(0-10 \mu \mathrm{M})$ in the presence of ${ }^{33} \mathrm{P}$-labeled ATP and a peptide (YIYGSFK), previously shown to be an excellent substrate for both Btk and Src family kinases. The kinase activity was measured using the thin-layer chromatography (TLC) technique. CTN06 was found to be an even more potent Btk inhibitor with an $\mathrm{IC}_{50}$ of $\sim 50 \mathrm{nM}$ compared with Etk $\left(\mathrm{IC}_{50} \approx 200 \mathrm{nM}\right)$ (Figure $3 \mathrm{~b}$ ). Inhibition was observed in a concentration-dependent manner. Src $\left(\mathrm{IC}_{50} \approx 5 \mu \mathrm{M}\right)$ and Mer $\left(\mathrm{IC}_{50}>10 \mu \mathrm{M}\right)$ were significantly more resistant to CTN06 inhibition (Figures $3 b$ and $c$ ). a
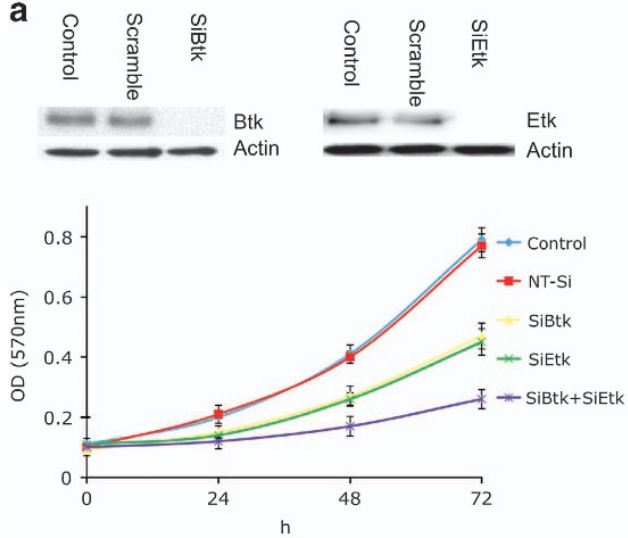

C

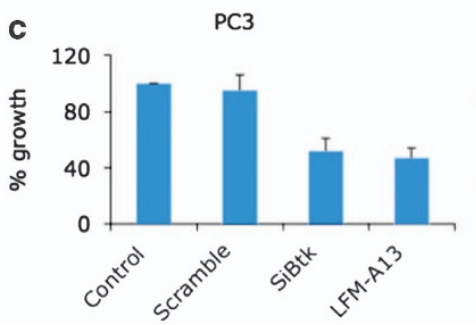

b
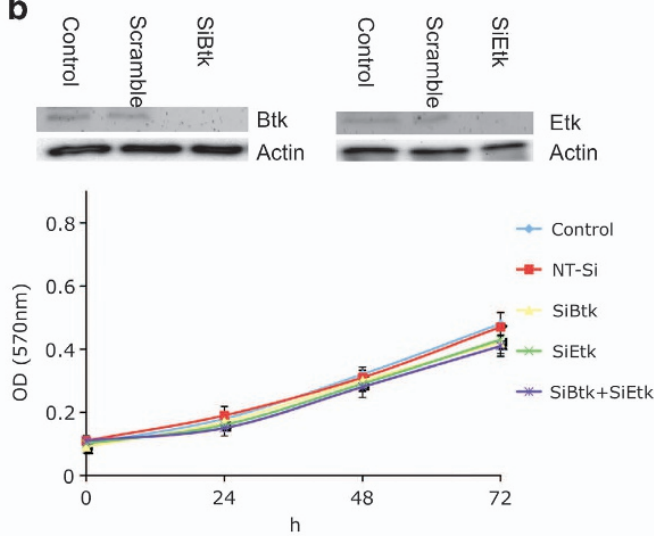

Du145

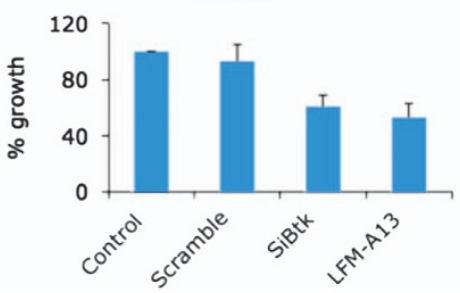

Figure 2 Both Btk/Etk (BMX) contribute to proliferation of prostate cancer cells. (a and $\mathbf{b}$ ) The expression of Etk and Btk in PC3 and RWPE1 cells was knocked down using the corresponding siRNA. The growth of the knockdown cells was measured using MTT assay. (c) The effect of Btk on prostate cancer cell growth was further confirmed using siBtk and LFM-A13 $(50 \mu \mathrm{M})$ in PC3 and Du145 cells. Columns, mean; bars, standard deviation, $n=3$ 
In addition to the Btk family tyrosine kinases, the inhibitory activity of CTN06 against other tyrosine kinases, including Itk, Lyn, Axl, Mer, EGFR and Abl, was investigated using the TLC assay. CTN06 appears to have the strongest activity toward Btk and Etk, followed by Itk, another member in the same family. No significant inhibitory activity toward any other kinases was observed (Figure 3d).
The inhibitor specificity is supported by the molecular docking studies. CTN06 is found to bind to the pocket of the ATP binding site with a binding energy of $-11 \mathrm{kcal} / \mathrm{mol}$ (Figures $3 e$ and f). Previous studies have shown kinase inhibitors that bind to this pocket. ${ }^{28,29}$ Further analysis through molecular dynamics reveals that CTN06 interacts with the 'gatekeeper' residue T474. CTN06 also interacts with the side a

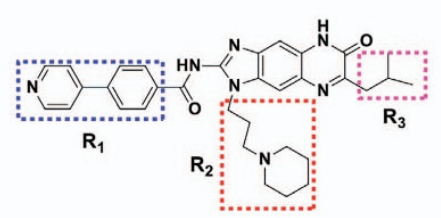

b

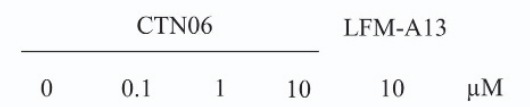

Btk

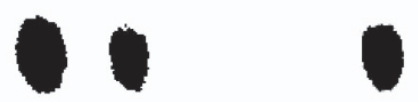

Etk

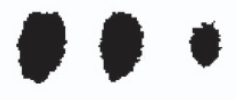

$\operatorname{Src}$

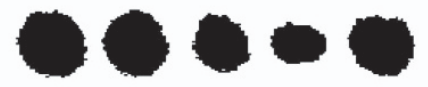

Mer

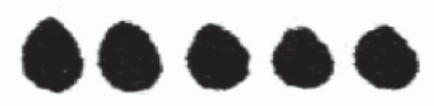

C
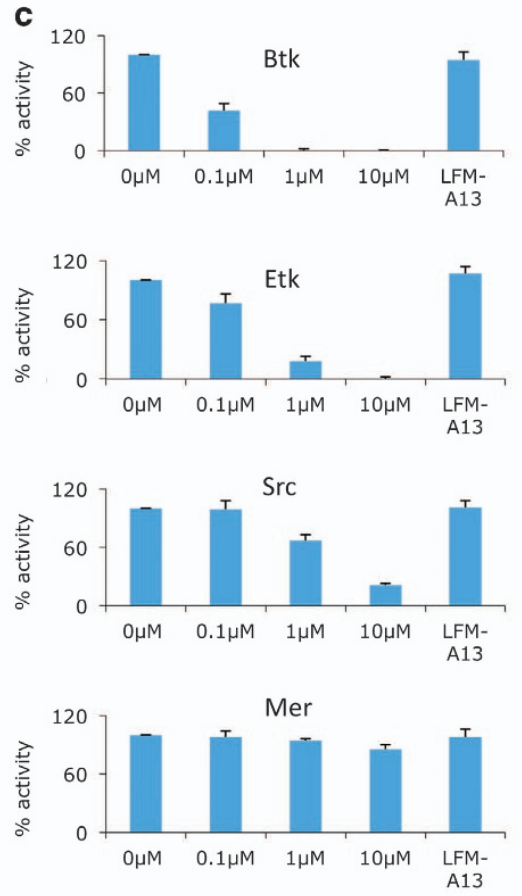

d Kinase inhibition profile of CTN06

\begin{tabular}{cc}
\hline Kinase & $\mathrm{IC}_{50}(\mu \mathrm{M})$ \\
\hline Btk & 0.05 \\
\hline Etk & 0.2 \\
\hline Itk & 0.5 \\
\hline Src & 5.0 \\
\hline Yes & $>10$ \\
\hline Lyn & $>10$ \\
\hline Axl & $>10$ \\
\hline Mer & $>10$ \\
\hline EGFR & $>10$ \\
\hline Abl & $>10$
\end{tabular}

e

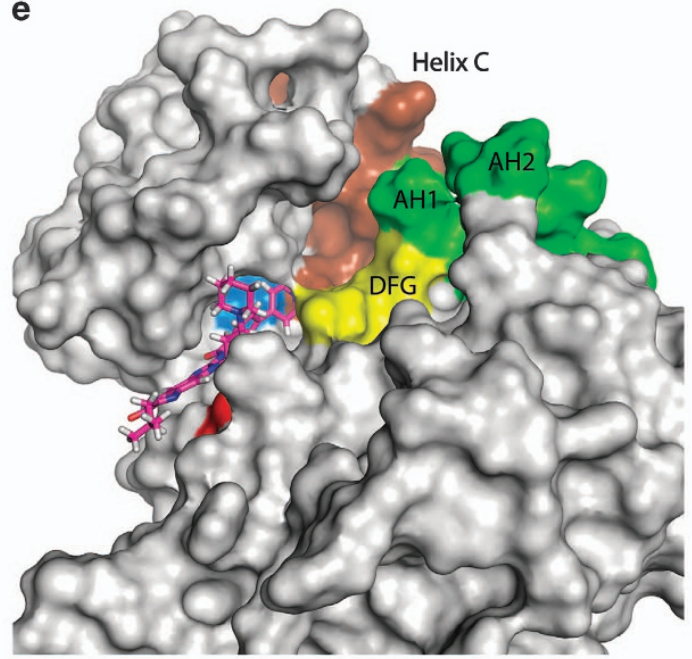

f

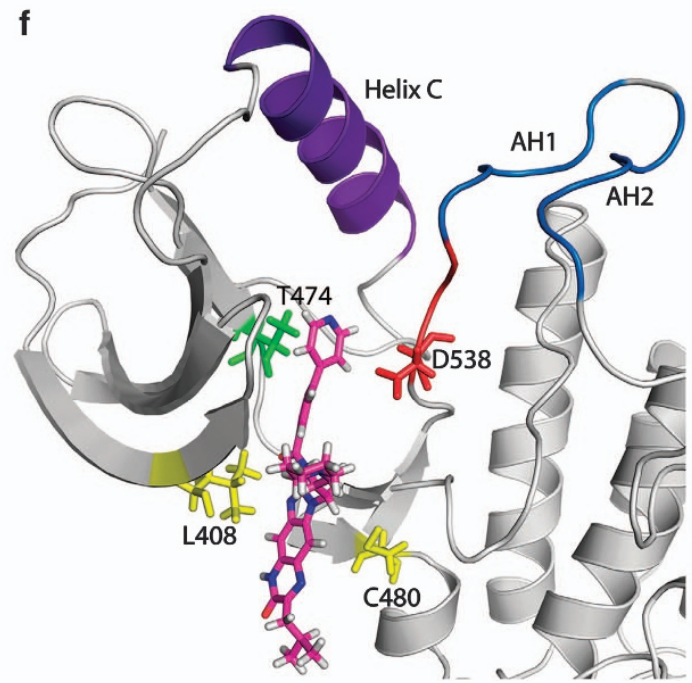

Figure 3 CTN06 is a potent Etk and Btk dual inhibitor. (a) Chemical structure of CTN06. (b) The potency of CTN06 to Btk, Etk, Src and Mer was measured using TLC to identify ${ }^{33}$ P-phosphorylated peptide substrate. Purified TKs $(20 \mathrm{nM})$, CTN06 $(0-10 \mu \mathrm{M})$ and the peptide substrate (YIYGSFK) were incubated with ${ }^{33} \mathrm{P}$-ATP in a kinase reaction. The resulting product was analyzed on a TLC plate. (c) The intensity of the radioactive spot was measured using densitometer. (d) Summarization of the kinase inhibition profile of CTN06. Columns, mean; bars, standard deviation, $n=3$. Molecular docking of CTN06 to Btk. (e) Surface view of Btk docked to CTN06 after 20 ns of MD relaxation. Brown: helix C (439-452); green: activation loop helix 1 (AH1) (541-546) and activation loop helix 2 (AH2) (548-553); yellow: DFG motif (538-540); blue: Thr474; red: Cys480. (f) Cartoon representation showing predicted interactions of Btk with CTN06. Thr474, Leu408, Cys480 and Asp538 side chains are shown as sticks and colored based on residue type (red: acidic, green: polar, yellow: non-polar). DFG motif is shown in red. Figures were generated using PyMol 
chains of $\mathrm{C} 480$, which is a residue unique to Btk when compared with other kinases. Previous studies have shown that only 8 kinases out of 491 that show T474 and C480 combination at these positions. ${ }^{28}$ Molecular dynamics studies reveal that CTN06-Btk binding is stable. We analyzed the molecular dynamics trajectories (Supplementary movie) and plotted putative hydrogen bonding and hydrophobic interactions between CTN06-Btk using LigPlot + (Supplementary Figure S2). CTN06 putatively forms multiple hydrophobic interactions with side chains of the pocket. The $R_{1}$ group interacts with T474, as well as the DFG motif that is important for kinase activity. $R_{2}$ and the three-ring core interact with the Glycine-rich loop region, as well as C480. Overall, computational studies show that CTN06 binds to Btk in a stable manner, and the interactions with the back pocket, gatekeeper threonine and the DFG motif lead to its kinase inhibitory properties.

CTN06 preferentially inhibits the growth of malignant prostate cells. To determine the effect of CTN06 on proliferation, a panel of cancer cell lines including LNCaP, Du145, PC3 and the immortalized normal prostate epithelial cell line, RWPE1, were incubated with CTN06 and their proliferation was measured using the MTT assay. CTN06 was very effective in inhibiting the growth of prostate cancer cells (PC3, Du145 and LNCaP), while RWPE1 was much more resistant to CTN06. The ability of CTN06 to inhibit Btk activation, based on phospho-Btk (pBTK) expression in those cells was confirmed using western blot (Figure 4a).

CTN06 induces autophagy in prostate cancer cells. Previously, we showed that the Src inhibitor AZD0530 induces autophagy in prostate cancer cells, which contributes to apoptosis resistance and diminishes the efficacy of the Src inhibitor. ${ }^{30}$ To determine whether CTN06 can trigger autophagy, PC3 cells stably transfected with GFP-LC3 were treated with CTN06 and then examined under fluorescence microscopy. After 2 and $24 \mathrm{~h}$ treatment with CTN06, these cells yielded extensive, distinct 'puncta' autophagosome morphology, whereas vehicle treatment did not. The ability of CTN06 to induce autophagy in PC3 cells was further confirmed by the conversion of endogenous LC3-I to the lipidated LC3-II forms. Addition of chloroquine (CQ), an autophagy blocker and lysosomal disruptor, resulted in the accumulation of larger autophagosomes, suggesting CTN06's effect is on the induction of autophagosome formation (Figure 4b).

CTN06 induces apoptosis in prostate cancer cells. To determine whether the growth inhibition induced by CTN06 on prostate cells was due to apoptosis, flow-cytometric analysis was carried out. Following treatment with CTN06 for $24 \mathrm{~h}$, a dose-dependent accumulation of a 'sub-G1' fraction was observed using propidium iodide $(\mathrm{PI})$ staining. Data based on Annexin- $V$ reactivity also indicated a dosedependent increase in apoptosis of PC3 cells following treatment with CTN06 (Figure 4c). The 'sub-G1' fraction only measures dead cells with DNA content loss, which may explain why it was less than the percentage of apoptotic cells measured by Annexin-V.
CTN06 inhibits prostate cancer cell migration. Tec-family tyrosine kinases have been shown to have an important role in cellular movement and cancer metastasis. To explore the ability of CTN06 to inhibit cell migration, 'wound healing' of PC3 cells was measured following treatment with CTN06. As shown in Supplementary Figure S3, 'wound healing' of PC3 cells was greatly inhibited by CTN06 after $16 \mathrm{~h}$. These results suggest that CTN06 has the ability not only to suppress prostate cancer cell growth, but also to inhibit cell migration, implicating CTN06 as an anti-metastasis agent.

CTN06 inhibits the phosphorylation of Btk, Etk and the downstream signal PLC $\gamma 2$, Stat3, Akt in prostate cancer cells. The inhibitory activity of CTN06 against phosphorylation of Etk and Btk in intact cells was examined by western blot. Btk as well as Etk phosphorylation in PC3 cells were significantly inhibited at 0.5 and $2 \mu \mathrm{M}$. The pPLC $\gamma 2$ inhibition is likely to result from Btk inhibition. A selective target for Etk is STAT3, ${ }^{31}$ whose phosphorylation is also inhibited by CTN06, so is Akt, another important downstream effector of Etk (Figure 5). Interestingly, Src phosphorylation was greatly inhibited in cells following treatment with CTN06 compared with kinase inhibition assay. This may be due to inhibition of Etk, which has been shown to cross activate Src. ${ }^{21}$

CTN06 modulates cancer-related miRNAs. Many miRNAs have been reported to have a role in carcinogenesis. To explore whether CTN06 modulates miRNAs, 272 miRNA levels in PC3 cells were examined using a microarray assay following treatment with CTN06. Among them, 22 exhibited alterations $>2$ folds, for most of which, there are no established functions in oncogenesis (Supplementary Figure S4a). A number of them, however, are known to possess oncogenic and tumor suppressive properties. We found that those miRNAs with tumor suppressive properties were generally upregulated, and those with oncogenic properties were downregulated following treatment with CTN06 (Supplementary Figure S4b). ${ }^{32-43}$ For instance, Mir-132, which is upregulated 29.9 folds following treatment with CTN06, has been reported to be downregulated by promoter methylation in prostate cancer cells. On the other hand, CTN06 downregulates Mir-421 ( -46.3 folds), which has been reported to downregulate ATM, a pro-apoptotic protein. ${ }^{42}$

CTN06 downregulates oncogenic-related genes. To further explore the mechanism of anti-cancer effect of CTN06 in prostate cancer cells, cDNA microarray assay was performed in PC3 cells following treatment with CTN06. Among the 772 genes examined, 57 genes were downregulated $>2$ folds. Interestingly, 25 of which are oncogenicrelated genes (Supplementary Figure S4c). Among those genes, Met, which is downregulated 2.1 folds following treatment with CTN06, has been reported to be constitutively activated in PC3 cells, and inhibition of Met led to significant inhibition of PC-3 cell proliferation, clonogenicity, migration and invasion. ${ }^{44} \mathrm{MYCBP}$, which is downregulated 2.1 folds by CTN06, is a positive regulator of Myc. Downregulation of MYCBP by miR22 suppresses oncogenic Myc activity. ${ }^{45}$

CTN06 has higher potency to inhibit prostate cancer cell growth compared with other kinase inhibitors. To further 

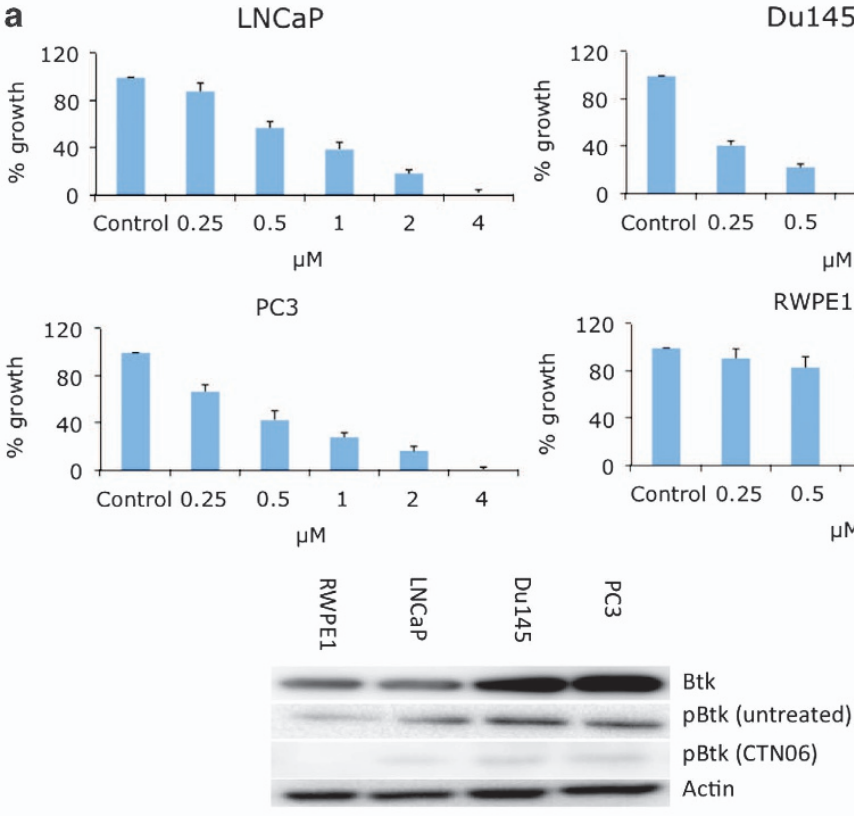

b
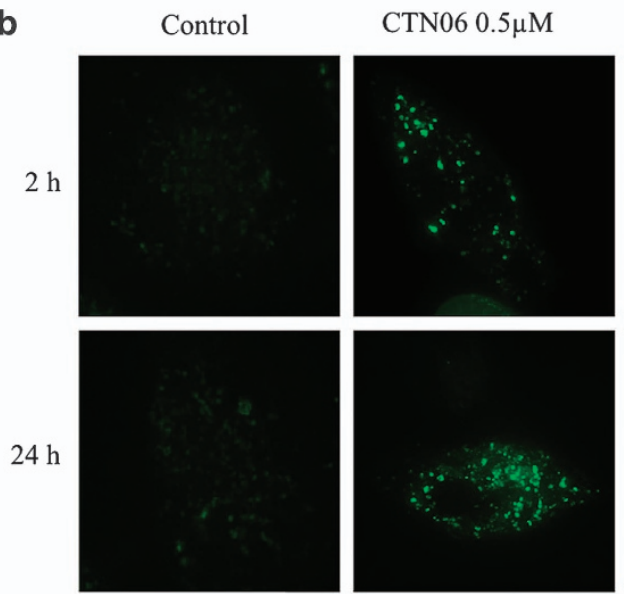

CTN06

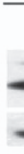

LC3 II : LC3 I
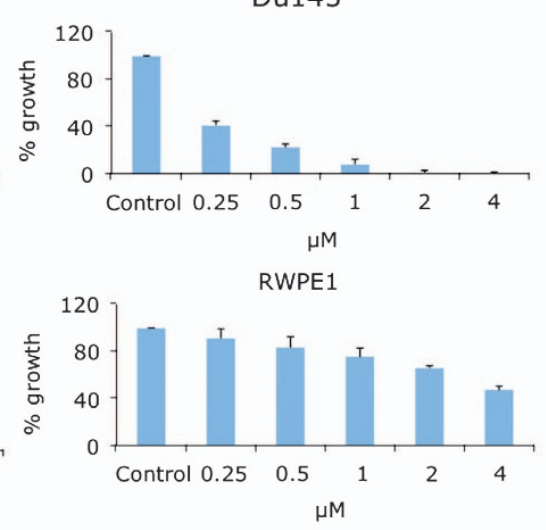

RWPE

Actin

\section{CTN06+CQ}

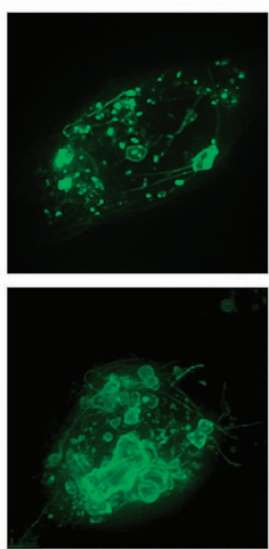

LC3 I

LC3 II

Actin
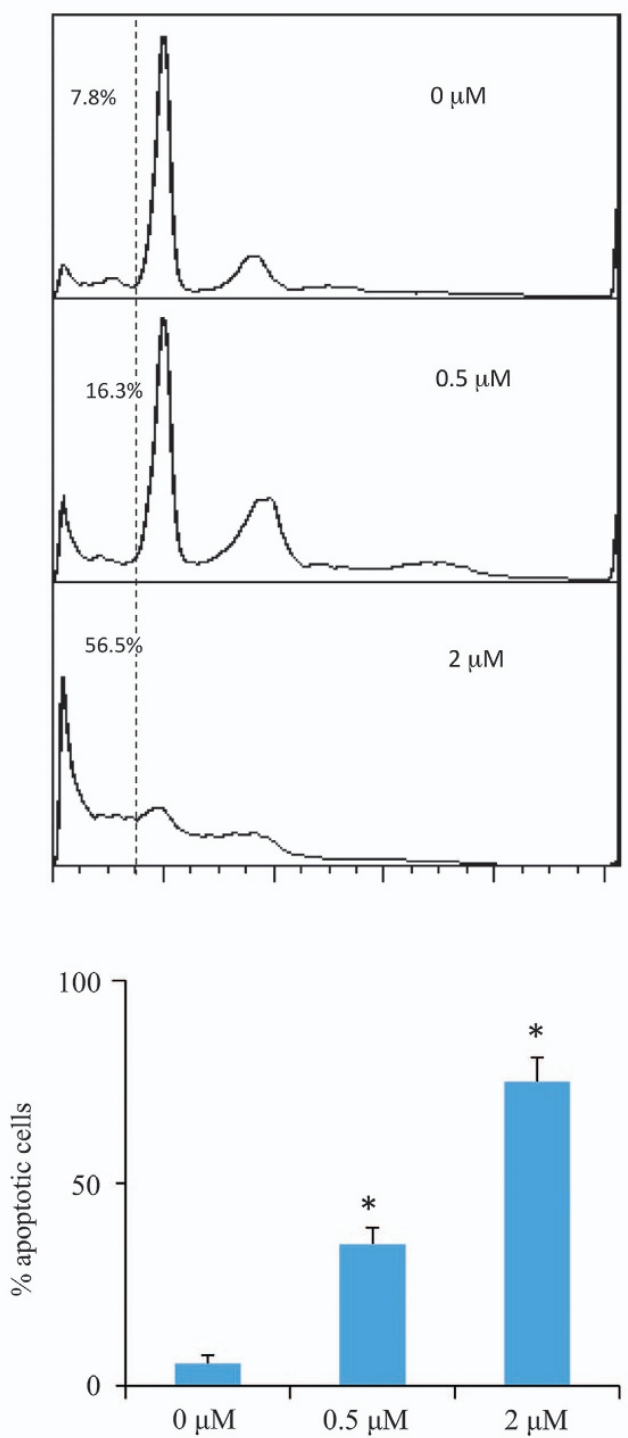

Figure 4 CTN06 induces autophagy as well as apoptosis in prostate cancer cells. (a) Growth inhibition of CTN06 to LNCaP, Du145, PC3 prostate cancer and normal prostate (RWPE1) cells. Cells were seeded at 5000 cells/well in 96-well plate overnight and treated with CTN06 at the indicated concentrations. The cell viability was measured using MTT assay after $72 \mathrm{~h}$. Columns, mean; bars, standard deviation, $n=3$. Inhibition of Btk by CTN06 ( $0.5 \mu \mathrm{M})$ in those cells was measured using western blot. (b) Induction of autophagy in PC3 cells by CTN06. PC3 cells were stably transfected with GFP-LC3 and were grown in 6-well plate to 50\% confluence and treated with CTN06. Autophagy was visualized by GFP-LC3 'puncta' at 2 and $24 \mathrm{~h}$ and immunoblot of endogenous LC3 isoforms $24 \mathrm{~h}$ after treatment. (c) Induction of apoptosis of PC3 cells following treatment with CTN06. PC3 cells were seeded at $10^{6}$ cells $/ \mathrm{ml}(2 \mathrm{ml})$ in a 6-well plate overnight and then treated with CTN06 at the indicated concentrations for $24 \mathrm{~h}$. Apoptosis was analyzed using PI staining as well as Annexin V-FITC apoptosis detection kit. Columns, mean; bars, standard deviation, $n=3$. In all, 0.5 and $2 \mu \mathrm{M}$ are significantly different from $0 \mu \mathrm{M}\left({ }^{*} P<0.05\right.$, one-way ANOVA with Tukey test for pairwise comparison)

explore the potency of CTN06 to prostate cancer cells, growth inhibitory activity of CTN06 to PC3 cells was compared with other kinase inhibitors including saracatinib (AZD0530), sorafenib, AG1478, 3ATA and LMF-A13. At $2 \mu \mathrm{M}$, CTN06 showed the highest potency to inhibit PC3 cell growth followed by sorafenib (Figure 6a). This result indicated that CTN06 is a potent inhibitor of prostate cancer cell growth.
CTN06 as a chemo-sensitizer. Our initial studies indicated that CTN06 has good cytotoxicity toward a panel of prostate cancer cells. To examine whether a Btk and Etk dual inhibitor works effectively as a chemo-sensitizer, PC3 cells were cotreated with CTN06 $(0.25 \mu \mathrm{M})$ and the autophagy inhibitor $\mathrm{CQ}(10 \mu \mathrm{M})$, or docetaxel (DTX) $(2 \mathrm{ng} / \mathrm{ml})$. Growth inhibition was determined using an MTT assay after $72 \mathrm{~h}$. Interestingly, 


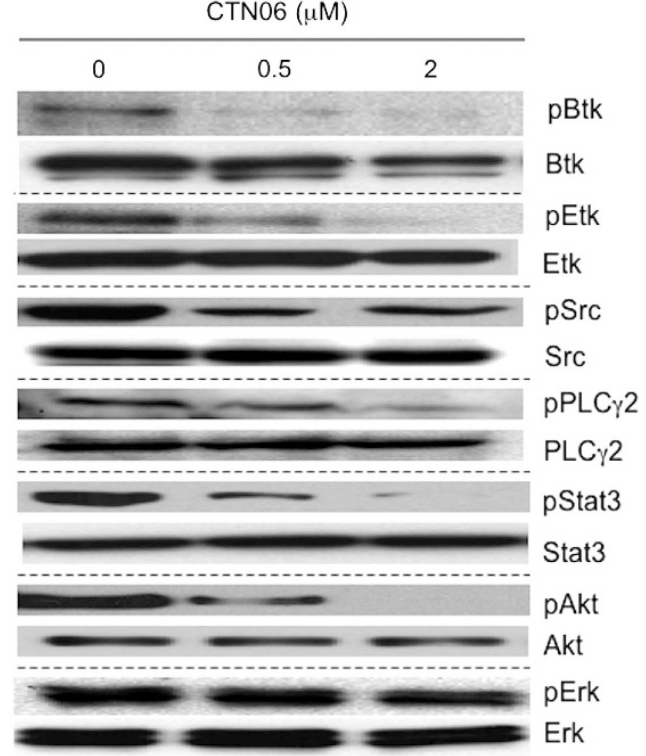

Figure 5 Inhibition of cell signaling in PC3 cells following treatment with CTN06. Cells were grown in $100-\mathrm{mm}$ plate to $50 \%$ confluence and treated with CTN06 at the indicated concentrations. Cells were harvested after $12 \mathrm{~h}$. pEtk, Etk, pBtk, Btk, pSrc, Src, pPLC $\gamma 2$, PLC $\gamma 2$, pStat3, Stat3, pAkt, Akt, pERK and ERK levels were measured using the corresponding antibodies by western blot. One of three similar experiments depicted

a synergistic effect of CTN06 was observed when prostate cancer cells were co-treated with $\mathrm{CQ}$. In the case of DTX co-treatment, less of a synergistic effect was observed when CTN06 and DTX were added to the cells at the same time, while a striking synergistic effect was observed when cells were treated with DTX for $24 \mathrm{~h}$ before treatment with CTN06 (Figure 6b). Annexin-V and PI staining further confirmed that combination of CTN06 and $\mathrm{CQ}$ induced apoptosis (Figure 6c). This suggests that CTN06 is a chemo-sensitizer, and blocking of autophagy by $\mathrm{CQ}$ promotes CTN06-induced cell death.

CTN06 inhibits PC3 xenograft tumor growth in vivo. Given the in vitro activity of CTN06 against prostate cancer cells, it is important to validate these results in vivo. PC3 cells were injected subcutaneously to nude mice. The mice were treated with vehicle (control) or CTN06 at $10 \mathrm{mg} / \mathrm{kg}$ daily via IP injection. As shown in Figures 7a and b, CTN06 decreased PC3 xenograft tumor growth without significant toxicity. Furthermore, Ki67 staining indicated that CTN06 inhibited tumor growth activity and cleaved caspase 3 staining indicated that it also induced apoptosis (Figure 7c). Western blot of LC3I to LC3II conversion suggested autophagy induction in PC3 xenograft tumors by CTN06 (Figure 7d).

\section{Discussion}

Tyrosine kinases have become important targets for drug development. Powerful combinatorial chemistry approaches and high-throughput screening assays have led to successful identification of many kinase inhibitors. ${ }^{46-48}$ Our previous work indicated that Etk is complexed with Src and FAK, and
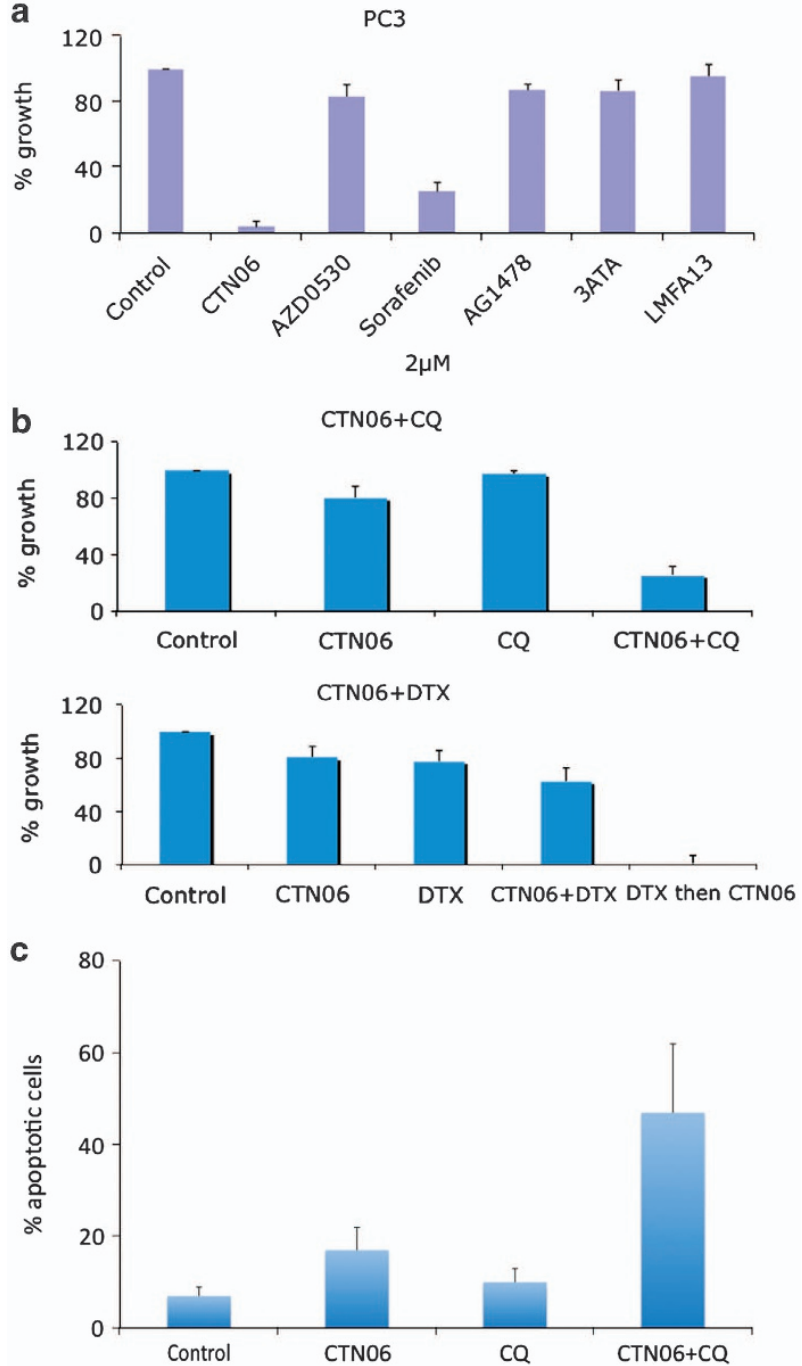

Figure 6 CTN06 as a chemo-sensitizer. (a) Comparison of CTN06 with other kinase inhibitors. PC3 cells were seeded at 5000 cells/well in 96-well plates overnight and treated with CTN06 or the other kinase inhibitors including AZD0530, sorafenib, AG1478, 3ATA and LMF-A13 at $2 \mu \mathrm{M}$. The cell viability was measured using MTT assay after $72 \mathrm{~h}$. (b) Growth inhibition of CTN06 and in combination with $10 \mu \mathrm{M}$ chloroquine (CQ) or $2 \mathrm{ng} / \mathrm{ml}$ docetaxel (DTX) to PC3 human prostate cancer cells. Cells were seeded at 5000 cells/well in 96 -well plate overnight and pretreated with the corresponding co-treatments for $1 \mathrm{~h}$, then treated with $0.25 \mu \mathrm{M}$ CTN06. The cell viability was measured using MTT assay after $72 \mathrm{~h}$. (c) The apoptotic effect of CTN06 in combination with CQ to PC3 cells was further measured using Annexin-V and PI staining and flow cytometry. Columns, mean; bars, standard deviation, $n=3$

has an important role in apoptosis, angiogenesis and metastasis of prostate cancer cells. ${ }^{22}$ Etk activation is a compensatory response to androgen deprivation, implicating its overexpression in castration-resistance transition. ${ }^{49}$ In addition, Etk interacts with p53 and controls the apoptosis pathway. ${ }^{25}$ Etk's role in other solid tumors including bladder cancer, hepatocellular carcinoma, nasopharyngeal carcinoma and breast cancer is well established. ${ }^{14-16,50}$ Etk has recently been implicated in the self-renewal and tumorigenic potential of glioblastoma stem cells. ${ }^{26}$ Etk, highly expressed in endothelial cells, has been shown to be a critical tyrosine kinase for angiogenesis and tumor growth. ${ }^{18}$ All these findings 

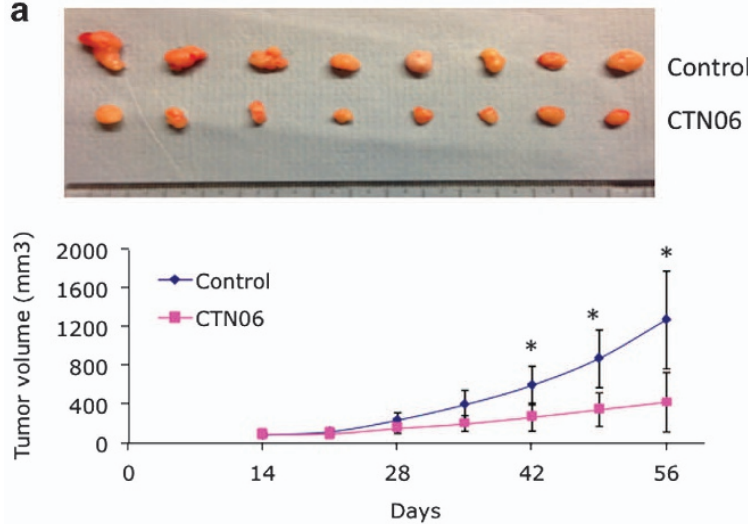

b

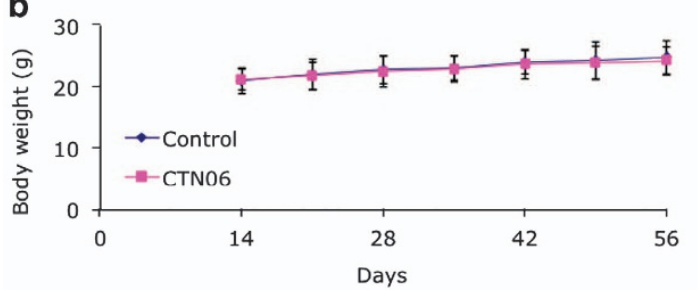

C
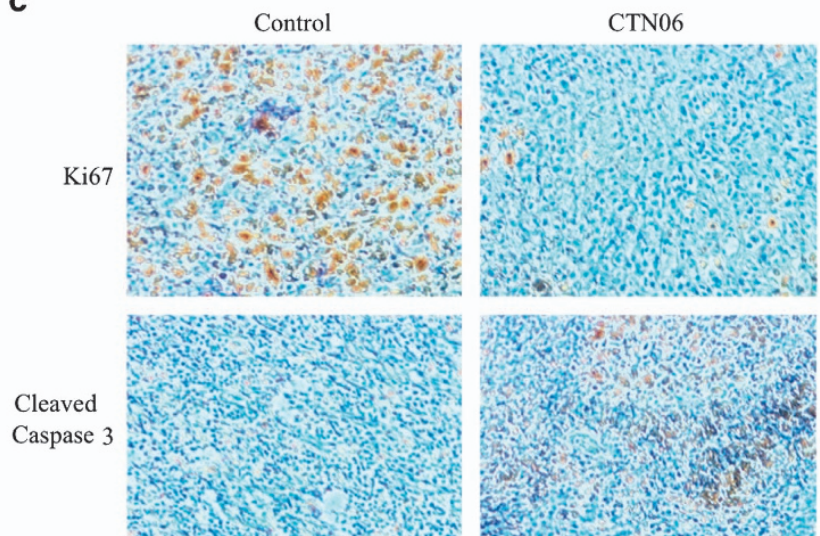

Cleaved
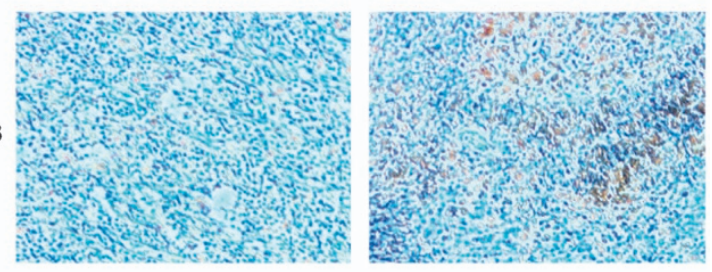

d

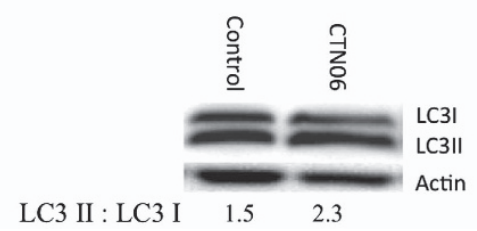

Figure 7 Inhibition of PC3 xenograft tumor growth by CTN06. $2 \times 10^{6} \mathrm{PC} 3$ cells were injected subcutaneously to nude mice. The tumors were grown to the indicated size and the mice were randomly divided into two groups ( 8 mice/group). The control group was treated with vehicle. The treatment group was treated with CTN06 at $10 \mathrm{mg} / \mathrm{kg}$ daily via IP injection. (a and $\mathbf{b})$ The tumor size and body weight were measured once a week. Marks, mean; bars, mean; $n=8\left({ }^{*} P<0.05\right.$, one-way ANOVA with Tukey test for pairwise comparison). (c and d) The tumor samples were further analyzed for Ki67 and cleaved caspase 3 using immunohistochemistry and LC3I to LC3II conversion using western blot

point to Etk as an appropriate therapeutic target. Yet, surprisingly little is known about Etk selective inhibitors. One recent report showed that an EGFR inhibitor, $\mathrm{Cl}-1033$, inhibits Etk at a sub-micromolar level via irreversible modification of a conserved cysteine residue. ${ }^{51}$ In this study, we set forth to identify a selective inhibitor for Etk.

Perhaps, the most striking observation of this study is the discovery that not only Etk is involved in prostate carcinogenesis, but also its close relative Btk. Previously, Btk was mainly reported in $B$ cells and $B$-cell malignancies. Btk inhibitors have been developed for the benefit of treating hematopoietic diseases. The role of Btk in solid tumors remains totally unknown. Here, we report that Btk is aberrantly expressed in prostate cancer tissues and cells. The Btk expression level increases with the higher grade tumors, and in the prostate cancer cell lines, it is expressed at a much higher level in androgen-independent cell lines than androgen-sensitive LNCaP cells or immortalized normal epithelial cells. Indeed, both Btk and Etk have a distinct but overlapping role in prostate cancer growth and survival. Knockdown of individual kinases attenuates the growth of PC3 cells, but simultaneous knockdown has greater effects. Thus, while we were screening for Etk inhibitors, we also look for those that inhibit both, and were able to identify CTN06 that inhibits both Etk and Btk and to a lesser extent, Itk. To our knowledge, this is the first selective Btk/Etk dual inhibitor reported to date.

CTN06 belongs to a novel class of reversible kinase inhibitors with a chemical structure distinct from other known TKIs. This inhibitor is most potent in inhibiting Btk followed by Etk. Compared with known Btk inhibitors, the inhibitory potency of CTN06 against Btk is about 100-fold stronger than LFM-A13 which is a reversible Btk inhibitor (Figure $3 b$ ). There are few Etk inhibitors reported so far. $\mathrm{Cl}-1033$ is a potent irreversible EGFR inhibitor with moderate Etk inhibition, but clinical study reported that $\mathrm{Cl}-1033$ is associated with severe toxicity. ${ }^{52}$ Therefore, a reversible Etk inhibitor such as CTN06 may have advantages and is probably less toxic. Treatment of PC3 cells with CTN06 resulted in the decrease in phosphorylation of Btk and Etk, as well as the downstream signals PLC $\gamma 2$, Stat3 and Akt. Interestingly, Src phosphorylation was greatly inhibited in cells following treatment with CTN06 compared with kinase inhibition assay. This is likely due to inhibition of Etk, which has been shown to crossactivate Src. 21 Significantly, CTN06 has much less effect on the growth of the immortalized normal prostate cell RWPE1, consistent with the Btk/Etk knockdown experimental results (Figure 2). While PC3 and DU145 have much higher expression level of Btk, LNCaP expresses both Etk and Btk about the same level as RWPE1; yet LNCaP appears to be more sensitive to CTN06 than RWPE1, suggesting that prostate cancer cells have adapted to the Etk/Btk pathway for growth and survival, much more so than normal prostate epithelial cells. This provides a strong rationale for targeting Btk/Etk pathway in prostate cancer cells. In addition, we and others previously reported that Src inhibitors such as saracatinib (AZD0530) or dasatinib, while effective in inhibiting metastasis, are generally not inducers of apoptosis, which is in part due to their ability to induce autophagy. ${ }^{30,53}$ By contrast, CTN-06 induces a high level of apoptosis, despite its ability to induce autophagy. This is likely due to the fact that Etk also interacts with and inactivates p53. Overexpression of Etk in prostate cancer cells is known to confer apoptosis resistance to androgen deprivation and photodynamic therapy. ${ }^{17,49}$ Given the antiapoptotic role of Btk in B-cell malignancies, it is likely that 
inhibition of Btk also contributes to the induction of apoptosis in prostate cancer cells. In addition, the effects of CTN06 on miRNAs could in part account for its ability to induce apoptosis in prostate cancer cells. This suggests that dual inhibitors of Btk/Etk, which connects to Src pathway, may offer a more effective alternative to Src inhibitors in terms of cell killing. Indeed, we found CTN06 is a much more effective growth inhibitor than AZD0530 (Figure 6a) as well as other currently approved anti-cancer drugs.

The finding that autophagy inhibitor $C Q$ further enhances the apoptosis-inducing effect of CTN06 suggests that here, like that in the case of other tyrosine kinase inhibitors, ${ }^{30}$ autophagy contributes partially to the survival of CTN06treated cells. Thus, autophagy inhibitor may be considered to enhance the efficacy of this compound. CTN06 is also a chemo-sensitizer and showed synergistic effect with DTX, indicating its potential role in combination therapy for prostate cancer. Interestingly, the sequence of its application is important. DTX followed by CTN06 is more effective than the reverse. This is understandable, as DTX action requires the cell-cycle movement to G2/M phase, which may be impeded if CTN06 was added first. Finally, consistent with Etk's role in cellular movement and as a co-activator of FAK, ${ }^{21}$ CTN06 was found to inhibit migration of prostate cancer cells. We thus anticipate that CTN06 should also have the ability to limit tumor metastasis. However, the genetic characters (e.g., AR and p53 status) of prostate cancer may influence their responses to drug treatment. Further investigation is desired to explore the effect of these factors to the response of prostate cancer cells to CTN06. ${ }^{54}$

In summary, we found that Btk is aberrantly expressed in prostate cancer, which together with Etk present suitable targets for therapy. We have identified a Btk and Etk dual inhibitor, CTN06, with good selectivity toward prostate cancer cells. Further evaluation of its pharmacokinetic and pharmacodynamic properties is underway. Btk and Etk dual inhibition holds exceptional promise as a novel treatment strategy for prostate cancer.

\section{Materials and Methods}

Reagents. Purified Etk, Btk, Itk, Mer, Yes, Lyn and Src kinases were obtained from Millipore Inc (Dundee, UK). PI, N,N-diisopropylethylamine (DIEA), N,Ndimethylformamide (DMF), ethanol, acetonitrile (ACN), N-Methyl-2-pyrrolidone (NMP), 1-(3-aminopropyl)piperidine, trifluoroacetic acid (TFA), Pd/C, ammonium formate, cyanogen bromide and dimethyl sulfoxide (DMSO) were purchased from Sigma-Aldrich (Saint Louis, MO, USA). L-Leucine methyl ester hydrochloride and 4-(4-pyridinyl)benzoic acid were purchased from Chem-Impex International Inc (Wood Dale, IL, USA). The Annexin V-FITC apoptosis detection kit was obtained from Abcam (Cambridge, MA, USA). Reverse-phase high-performance liquid chromatography (RP-HPLC) from the Waters Corporation (Milford, MA, USA) was used for analysis and purification of CTNO6.

Synthesis of CTN06. In brief, a solution of L-leucine methyl ester hydrochloride $(545.1 \mathrm{mg}, 3.0 \mathrm{mmol})$ and DIEA $(1.15 \mathrm{ml}, 6.6 \mathrm{mmol})$ in DMF $(4.5 \mathrm{ml})$ was added dropwise under vigorous stirring to a solution of 1,5-difluoro2,4-dinitrobenzene $(612.0 \mathrm{mg}, 3.0 \mathrm{mmol})$ in DMF $(1.5 \mathrm{ml})$. The reaction solution was stirred at room temperature for $45 \mathrm{~min}$. This was followed by the addition of a solution of 1-(3-aminopropyl) piperidine $(477 \mu \mathrm{l}, 3.0 \mathrm{mmol})$ and DIEA $(522.6 \mu \mathrm{l}$, $3.0 \mathrm{mmol}$ ) in DMF $(2 \mathrm{ml})$. The resulting mixture was agitated at room temperature overnight. Ethanol $(60 \mathrm{ml}), \mathrm{Pd} / \mathrm{C}(10 \%, 600 \mathrm{mg})$ and ammonium formate $(4.5 \mathrm{~g}, 71.4 \mathrm{mmol})$ were added to the solution. The solution was heated to reflux for $4 \mathrm{~h}$ and then cooled to room temperature. The $\mathrm{Pd} / \mathrm{C}$ was filtered out and the filtrate was concentrated with a rotary evaporator. The residue was re-dissolved in ethanol $(40 \mathrm{ml})$, followed by addition of cyanogen bromide $(321.3 \mathrm{mg}, 3.6 \mathrm{mmol})$. The resulting mixture was stirred at room temperature for $12 \mathrm{~h}$. The precipitate was collected by filtration and washed with ethanol, three times. The solid was dried in vacuum and used for the next step without further purification. A portion of the solid $(382.5 \mathrm{mg}$, $1.0 \mathrm{mmol}$ ) was weighed out and re-dissolved in NMP $(1 \mathrm{ml})$, and was added the solution of 4-(4-pyridinyl)benzoic acid $(199.2 \mathrm{mg}, 1.0 \mathrm{mmol}), H B T U$ (379.3 mg, $1.0 \mathrm{mmol})$ and DIEA $(348.4 \mu \mathrm{l}, 2.0 \mathrm{mmol})$ in NMP $(3 \mathrm{ml})$. The resulting solution was stirred at room temperature overnight. The precipitate was collected by filtration and washed with ethanol followed by RP-HPLC purification. The fraction was collected and lyophilized to give a yellow powder as the final product (Supplementary Figure S1). The homogeneity of the compound was checked by analytical RP-HPLC. The purity was determined to be $>95 \%$ pure. The identity of the compound was confirmed by matrix-assisted laser desorption/ionization-time of flight mass spectrometry, found: 564.28 Dalton (calculated: 564.31 Dalton for $\mathrm{MH}^{+}$).

Cell culture. RWPE1, LNCaP, Du145 and PC3 cells were obtained from ATCC (Manassas, VA, USA) and maintained in RPMI-1640 medium containing $10 \%$ fetal bovine serum and $1 \%$ penicillin/streptomycin/glutamine.

Tissue microarray. The expression level of Btk in prostate cancer tissue was examined using tissue microarray (PROS-006) from the UC Davis Pathology department. The array was stained with anti-Btk antibody (Santa Cruz Inc., Santa Cruz, CA, USA; sc-1107). The array contains 28 benign, 48 Gleason 6 (CaP 6), 46 Gleason 8 ( $\mathrm{CaP} 8)$ prostate cancer samples. The expression level of Btk was graded as no, low and high as illustrated in Figure 1a by an expert pathologist.

Btk ELISA. Btk levels in RWPE1, LNCaP, Du145 and PC3 cells were further measured using the Btk ELISA assay kit (Abnova Inc., Littleton, CO, USA; KA2617) according to the manufacturer's protocol.

Reverse transcription and quantitative real-time PCR. Reverse transcription and quantitative real-time PCR (qRT-PCR) were done as described previously. ${ }^{30}$ Primer sequences used to amplify Btk fragments are listed as follows: forward 5'-GGTGGAGAGCACGAGATAAA-3'; reverse 5'-CCGAGTCATG TGTTTGGAATAC-3' (IDTDNA Inc., Coralville, IA, USA). GAPDH was used as the housekeeping gene.

Etk and Btk knockdown assay. Etk and Btk expression in PC3 and RWPE1 cells was knocked down using siRNA. The Btk (Smartpool), Etk (Smartpool) siRNA and non-targeted RNA were obtained from Dharmacon Inc. (Lafayette, CO, USA). The siRNAs were transfected to cells according to the manufacturer's instruction. The expression levels of Btk and Etk were examined using a western blot after $48 \mathrm{~h}$. The growth rates were examined daily using an MTT assay for 3 days. For comparison of SiBtk and LFM-A13, PC3 and Du145 cells were seeded at 5000 cells/well in 96-well plate overnight. Then, the cells were transfected with SiBtk or treated with $50 \mu \mathrm{M}$ LFM-A13, cell viability was examined using an MTT assay at $72 \mathrm{~h}$.

Kinase inhibition assay. Kinase inhibition was measured using TLC. Briefly, purified kinases $(20 \mathrm{nM})$, the corresponding substrate $(500 \mu \mathrm{M}$, TSFYGRH for Etk, YIYGSFK for the other kinases) and CTN06 $(0-10 \mu \mathrm{M})$ were incubated in a kinase reaction (100 mM Hepes, $\mathrm{pH} 7.4,10 \mathrm{mM} \mathrm{MnCl}_{2}, 10 \mathrm{mM} \mathrm{MgCl}_{2}, 1 \mathrm{mM}$ DTT) for $5 \mathrm{~min}$, and the reaction was started by adding $5 \mu \mathrm{Ci}{ }^{33} \mathrm{P}$-labaled ATP. The reaction $(10 \mu \mathrm{l})$ was incubated at room temperature for $1 \mathrm{~h}$ and was stopped by adding $10 \mu \mathrm{L} \mathrm{H}_{3} \mathrm{PO}_{4}$. The radioactivity of the peptide substrate was analyzed using TLC as previously described. ${ }^{55}$

Molecular modeling. Molecular docking studies were performed to determine the preferred binding site of CTN06 on the Btk structure. An energy optimized structure of CTN06 was calculated using Merck Molecular Force Field (MMFF) as implemented in Marvin Suite v 5.11 (http://www.chemaxon.com/ products/marvin). The crystal structure of Btk (PDB ID: 1K2P) that corresponds to amino-acid positions 397-654 was used in our modeling studies. To define a putative binding site for CTN06 on Btk protein structure, we first used a blind docking approach, implemented on the SwissDock web service (http://swissdock.vital-it.ch). ${ }^{56}$ Among the clusters generated by SwissDock, the conformation with the lowest binding free energy was selected. To further confirm the binding site predicted by blind docking, we used Autodock v4.2. Btk and 
CTN06 structures were prepared for docking using an Autodock Tools package. ${ }^{57}$ Partial atomic charges were assigned to CTN06 using the Gasteiger-Marsili method, and, after the merging of non-polar hydrogens, rotatable bonds were assigned using Autodock Tools. All the water molecules were removed from the Btk structure, and the missing hydrogens and Kollman partial charges were added. Further, non-polar hydrogens were merged to their corresponding carbons, and for each atom the desolvation parameters were assigned. We used a grid size of $60 \times 60 \times 60$ with grid spacing of 0.375 angstroms. The grid size was selected to fit the whole ligand molecule. We used the Lamarckian Genetic Algorithm, called Pseudo Solis-Wets Algorithm, to perform 256 independent docking runs with default parameters in Autodock. ${ }^{58}$ Cluster analysis was performed on docked results using an RMS tolerance of 2 angstroms.

To further understand the stability and dynamics of the ligand-kinase complex, we performed a 20-ns molecular dynamics (MD) simulation, starting with the bestdocked structure predicted by Autodock-independent runs. These simulations were performed using NAMD v $2.7 \mathrm{~b} 2 .{ }^{59} \mathrm{CHARMM} 27$ force fields were used to calculate the potentials of Btk, while CHARMM22 (as implemented in SwissParam, http:// swissparam.ch $)^{60}$ force fields were used to calculate the potentials of CTN06. The kinase-ligand complex was solvated in a water box with periodic boundary conditions. Dimensions of the water box were selected to be at least 10 angstroms larger than the solute in every direction. The whole system was neutralized with $0.15 \mathrm{M} \mathrm{NaCl}$. An initial minimization step was performed for 6000 steps, followed by $20 \mathrm{~ns}$ of relaxation. Trajectories of these simulations were visualized using VMD v 1.9 (http://www.ks.uiuc.edu/Research/vmd/vmd-1.9/) and the interactions between the kinase and the ligand were plotted using LigPlot + v 1.4 and PyMol (http:// www.schrodinger.com/pymol/).

Western blotting. Western blotting was performed as described previously. ${ }^{61}$ Cells were grown in $100 \mathrm{~mm}$ dishes to about $50 \%$ confluence and treated with vehicle (control) and CTN06 $(0.5$ and $2 \mu \mathrm{M})$ for $12 \mathrm{~h}$. Proteins were detected by the following antibodies: $\beta$-actin (Sigma-Aldrich, A1978), Btk (Santa Cruz Inc., sc-1107), pBtk (pY233, Abcam, ab68217), Etk (Santa Cruz Inc., sc8874), pEtk (pY40, 3211S), Src (2109), pSrc (pY416, 6943), PLC $\gamma 2$ (3872), pPLC $\gamma 2$ (pY759, 6943), Stat3 (12640), pStat3 (pY705, 4113), ERK (4696) and pERK (4695) were obtained from Cell Signaling Inc. (Beverly, MA, USA). For pBtk and pEtk, cells were pre-treated with $100 \mu \mathrm{M}$ pervanadate for $15 \mathrm{~min}$ before harvest.

MTT assay. Cells were seeded in 96-well plates and cultured overnight, followed by treatment with $0.1 \%$ DMSO, as a vehicle control, and CTN06 at the indicated concentrations for $72 \mathrm{~h}$. Growth inhibition was measured using a 3-(4,5Dimethylthiazol-2-yl)-2,5-diphenyltetrazolium bromide (MTT) assay (Roche Diagnostic, Mannheim, Germany) according to the manufacturer's protocol.

Flow cytometry. PC3 cells were treated with $0.1 \%$ DMSO (control) and CTN06 at the indicated concentrations for $24 \mathrm{~h}$. Cell-cycle arrest was determined by the incorporation of propidium iodide (Sigma-Aldrich) into permeabilized cells. Cells undergoing apoptosis were identified using an Annexin V-FITC kit (Abcam), following the manufacturer's instructions. The cells were analyzed using a Coulter Epics XL flow cytometer (Beckman Coulter, Miami, FL, USA).

Microarray assay for miRNAs and cDNAs. PC3 cells were seeded at $10^{6}$ cells/well in 6-well plate and treated with $0.5 \mu \mathrm{M}$ CTN06 for $18 \mathrm{~h}$. Cells were harvested and RNA was isolated using a trizol reagent (Ambion Inc., Grand Island, NY, USA). Total RNA samples were submitted to the UC Davis Comprehensive Cancer Center's Genomics Shared Resource (GSR) for microarray profiling of gene and miRNA expression and subsequent data analysis. The methods are briefly described below.

Comprehensive gene expression profiling was performed with Affymetrix GeneChip Human Genome U133 Plus 2.0 (HG-U133 Plus 2.0) (Affymetrix Inc., Santa Clara, CA, USA) arrays according to standard protocols described by the manufacturer. Normalized probe set expression intensities were obtained using robust multi-array average (RMA) for probe summarization and normalization of background-adjusted and log-transformed perfect match probe intensity values. The data set was filtered to retain only those probe sets having expression values that exceeded the $5 \%$ lower cutoff threshold in at least one of the samples. Comparison analysis was then performed to identify genes that were differentially expressed between CTN06- and vehicle-treated cells. Criteria for the selection of genes exhibiting significant expression changes included an average fold change of $\geq 2.0$ between groups and $P$-values of $\leq 0.05$. Global analysis of miRNA expression was performed with Agilent Human miRNA Microarrays (Release 16.0) (Agilent Technologies, Santa Clara, CA, USA) as per the manufacturer's standard protocols. Background-subtracted signal intensity values were log-transformed, quantile-normalized and baseline transformed with GeneSpring GX12 software (Agilent Technologies). The data set was then filtered for miRNAs exhibiting $\geq 1.5$ fold differential expression in CTN06-treated cells relative to that of the vehicletreated controls. The miRNA profile was examined using GeneChip miRNA 2.0 Array (Affymetrix Inc.) and the gene expression profile was examined using CDNA microarray (Affymetrix Inc.) by UC Davis Genome Center.

Autophagy assay. PC3 cells were stably transfected with GFP-LC3, as previously described. ${ }^{30}$ Cells were grown in a 6 -well plate to $50 \%$ confluence and treated with $5 \mu \mathrm{M}$ CTN06 for $24 \mathrm{~h}$. Autophagy was visualized by GFP-LC3 'puncta' and immunoblot of Endogenous LC3 isoforms under an Olympus BX61 motorized reflected fluorescence microscope with FITC filter (excitation, $480 \mathrm{~nm}$; emission, $535 \mathrm{~nm}$ ) (Olympus America Inc., Melville, NY, USA) by using the SlideBook4.1 software (Intelligent Imaging Innovations, Denver, CO, USA).

PC3 cell 'wound healing' assay. PC3 cells were grown in 6-well plate to $60 \%$ confluency. Then wounds were made using a tip and treated with CTN06 (0 and $0.5 \mu \mathrm{M}$ ). Cell migration (wound healing) was visualized under microscope at the indicated times.

CTN06 as a chemo-sensitizer. Growth inhibition of CTN06 in combination with $10 \mu \mathrm{M} \mathrm{CQ}, 2 \mathrm{ng} / \mathrm{ml}$ DTX or $1 \mu \mathrm{M}$ AZD0530 (AZD), to PC3 human prostate cancer cells was evaluated. Cells were seeded at 5000 cells/well in a 96 -well plate overnight and pre-treated with the corresponding co-treatments for $1 \mathrm{~h}$, then treated with $0.25 \mu \mathrm{M}$ CTN06. The cell viability was measured using an MTT assay after $72 \mathrm{~h}$.

Inhibition of PC3 xenograft tumor growth by CTN06. Animal experimental conditions were in accordance with the protocol approved by the Institutional Animal Care and Use Committee at the University of California, Davis. In all, $2 \times 10^{6}$ PC3 were injected subcutaneously to 5 - to 6 -week-old male nude mice. Mice were randomly divided into two groups and treated with buffer only (control) or $10 \mathrm{mg} / \mathrm{kg} /$ day CTN06 daily starting from 14 days after injection. The size of tumors and body weight were measured once a week. After 42 days treatment, mice were killed and tumors were harvested frozen in liquid nitrogen and stored at $-80^{\circ} \mathrm{C}$. Paraffin-embedded tumor tissues were sectioned to $5-\mu \mathrm{m}$ thickness and mounted on positively charged microscope slides, and $1 \mathrm{mM}$ EDTA $(\mathrm{pH}$ 8.0) was used for antigen retrieval. Immunohistochemistry was performed using 1:200 dilution of Ki67 antibody (Cell Signaling Inc., 9027) and 1:50 dilution of cleaved caspase 3 antibody (Cell Signaling Inc., 9664). Western blots were performed using tumor lysates with LC3 antibody (Cell Signaling Inc., 4599).

Statistics. A one-way ANOVA was used in combination with a Tukey test for pairwise comparison. $P$-values of $<0.05$ were considered as significant.

\section{Conflict of Interest}

Both KSL and HJK are scientific advisors for C-TAG Inc.

Acknowledgements. This work was in part supported by C-TAG Bioscience Inc (Research grant to RL), NIH grants DOH102-TD-M-111-102001 (to HJK), NSC 102-2320-B-400-018-MY3 (to HJK), and 03A1-MGPP18-014 (to HJK), DK52659 CA150197 (to HJK) and CA098116 (to KSL); DOD Postdoctoral Training Award PC080859 and Auburn Community Cancer Endowment Fund (to WG); DOD Postdoctoral Training Award PC121738 (to GB); and a Stand Up to CancerProstate Cancer Foundation Prostate Dream Team Translational Cancer Research Grant. This research grant is made possible by the generous support of the Movember Foundation. Stand Up To Cancer is a program of the Entertainment Industry Foundation administered by the American Association for Cancer Research.

1. Jemal A, Siegel R, Ward E, Hao Y, Xu J, Murray T et al. Cancer statistics 2008. CA Cancer J Clin 2008; 58: 71-96.

2. Stommel JM, Kimmelman AC, Ying H, Nabioullin R, Ponugoti $A H$, Wiedemeyer $R$ et al. Coactivation of receptor tyrosine kinases affects the response of tumor cells to targeted therapies. Science 2007; 318: 287-290. 
3. Honda F, Kano H, Kanegane H, Nonoyama S, Kim ES, Lee SK et al. The kinase Btk negatively regulates the production of reactive oxygen species and stimulation-induced apoptosis in human neutrophils. Nat Immunol 2012; 13: 369-378.

4. Conley ME, Dobbs AK, Farmer DM, Kilic S, Paris K, Grigoriadou S et al. Primary B cell immunodeficiencies: comparisons and contrasts. Annu Rev Immunol 2009; 27 199-227.

5. Gray P, Dunne A, Brikos C, Jefferies CA, Doyle SL, O'Neill LA. MyD88 adapter-like (Mal) is phosphorylated by Bruton's tyrosine kinase during TLR2 and TLR4 signal transduction. J Biol Chem 2006; 281: 10489-10495.

6. Khare A, Viswanathan B, Gund R, Jain N, Ravindran B, George A et al. Role of Bruton's tyrosine kinase in macrophage apoptosis. Apoptosis 2011; 16 334-346.

7. Herman SE, Gordon AL, Hertlein E, Ramanunni A, Zhang X, Jaglowski $S$ et al. Bruton tyrosine kinase represents a promising therapeutic target for treatment of chronic lymphocytic leukemia and is effectively targeted by PCI-32765. Blood 2011; 117 6287-6296.

8. Rushworth SA, Bowles KM, Barrera LN, Murray MY, Zaitseva L, MacEwan DJ. BTK inhibitor ibrutinib is cytotoxic to myeloma and potently enhances bortezomib and lenalidomide activities through NF- $\mathrm{KB}$. Cell Signal 2013; 25 106-112.

9. Mahajan S, Ghosh S, Sudbeck EA, Zheng Y, Downs S, Hupke M et al. Rational design and synthesis of a novel anti-leukemic agent targeting Bruton's tyrosine kinase (BTK), LFM-A13 [alpha-cyano-beta-hydroxy-beta-methyl-N-(2, 5-dibromophenyl)propenamide] J Biol Chem 1999; 274: 9587-9599.

10. de Rooij MF, Kuil A, Geest CR, Eldering E, Chang BY, Buggy JJ et al. The clinically active BTK inhibitor $\mathrm{PCl}-32765$ targets B-cell receptor- and chemokine-controlled adhesion and migration in chronic lymphocytic leukemia. Blood 2012; 119 2590-2594.

11. Winer ES, Ingham RR, Castillo JJ. PCI-32765: a novel Bruton's tyrosine kinase inhibitor for the treatment of lymphoid malignancies. Expert Opin Investig Drugs 2012; 21: 355-361.

12. Chang BY, Huang MM, Francesco M, Chen J, Sokolove J, Magadala P et al. The Bruton tyrosine kinase inhibitor PCl-32765 ameliorates autoimmune arthritis by inhibition of multiple effector cells. Arthritis Res Ther 2011; 13: R115.

13. Tai YT, Chang BY, Kong SY, Fulciniti M, Yang G, Calle $Y$ et al. Bruton tyrosine kinase inhibition is a novel therapeutic strategy targeting tumor in the bone marrow microenvironment in multiple myeloma. Blood 2012; 120: 1877-1887.

14. Guo S, Sun F, Guo Z, Li W, Alfano A, Chen H, Magyar CE et al. Tyrosine kinase ETK/BMX is up-regulated in bladder cancer and predicts poor prognosis in patients with cystectomy. PLoS One 2011; 6: e17778.

15. Zhang Z, Zhu W, Zhang J, Guo L. Tyrosine kinase Etk/BMX protects nasopharyngeal carcinoma cells from apoptosis induced by radiation. Cancer Biol Ther 2011; 11: 690-698.

16. Guo L, Guo Y, Xiao S. Expression of tyrosine kinase Etk/Bmx and its relationship with AP-1- and NF-kappaB-associated proteins in hepatocellular carcinoma. Oncology 2007; 72: $410-416$.

17. Xue LY, Qiu Y, He J, Kung HJ, Oleinick NL. Etk/Bmx, a PH-domain containing tyrosine kinase, protects prostate cancer cells from apoptosis induced by photodynamic therapy or thapsigargin. Oncogene 1999; 18: 3391-3398.

18. Chang YM, Kung HJ, Evans CP. Nonreceptor tyrosine kinases in prostate cancer. Neoplasia 2007; 9: 90-100.

19. Dai B, Kim O, Xie Y, Guo Z, Xu K, Wang B et al. Tyrosine kinase Etk/BMX is up-regulated in human prostate cancer and its overexpression induces prostate intraepithelial neoplasia in mouse. Cancer Res 2006; 66: 8058-8064.

20. Holopainen T, López-Alpuche V, Zheng W, Heljasvaara R, Jones D, He Y et al. Deletion of the endothelial $\mathrm{Bmx}$ tyrosine kinase decreases tumor angiogenesis and growth. Cancer Res 2012; 72: 3512-3521.

21. Lee LF, Guan J, Qiu Y, Kung HJ. Neuropeptide-induced androgen independence in prostate cancer cells: roles of nonreceptor tyrosine kinases Etk/Bmx, Src, and focal adhesion kinase. Mol Cell Biol 2001; 21: 8385-8397.

22. Chen R, Kim O, Li M, Xiong X, Guan JL, Kung HJ et al. Regulation of the PH-domaincontaining tyrosine kinase Etk by focal adhesion kinase through the FERM domain. Nat Cell Biol 2001; 3: 439-444.

23. Jiang X, Borgesi RA, McKnight NC, Kaur R, Carpenter CL, Balk SP. Activation of nonreceptor tyrosine kinase Bmx/Etk mediated by phosphoinositide 3-kinase, epidermal growth factor receptor, and ErbB3 in prostate cancer cells. J Biol Chem 2007; 282: 32689-32698.

24. Qiu Y, Robinson D, Pretlow TG, Kung HJ. Etk/Bmx, a tyrosine kinase with a pleckstrinhomology domain, is an effector of phosphatidylinositol 3'-kinase and is involved in interleukin 6-induced neuroendocrine differentiation of prostate cancer cells. Proc Nat Acad Sci USA 1998; 95: 3644-3649.

25. Jiang T, Guo Z, Dai B, Kang M, Ann DK, Kung HJ et al. Bi-directional regulation between tyrosine kinase Etk/BMX and tumor suppressor p53 in response to DNA damage. J Biol Chem 2004; 279: 50181-50189.

26. Guryanova $\mathrm{OA}$, Wu Q, Cheng L, Lathia JD, Huang Z, Yang J et al. Nonreceptor tyrosine kinase BMX maintains self-renewal and tumorigenic potential of glioblastoma stem cells by activating STAT3. Cancer Cell 2011; 19: 498-511.
27. Chau CH, Chen KY, Deng HT, Kim KJ, Hosoya K, Terasaki T et al. Coordinating Etk/Bmx activation and VEGF upregulation to promote cell survival and proliferation. Oncogene 2002; 21: 8817-8829

28. Lou Y, Owens TD, Kuglstatter A, Kondru RK, Goldstein DM. Bruton's tyrosine kinase inhibitors: approaches to potent and selective inhibition, preclinical and clinical evaluation for inflammatory diseases and B cell malignancies. J Med Chem 2012; 55: 4539-4550.

29. Kuglstatter A, Wong A, Tsing S, Lee SW, Lou Y, Villaseñor AG et al. Insights into the conformational flexibility of Bruton's tyrosine kinase from multiple ligand complex structures. Protein Sci 2011; 20: 428-436.

30. Wu Z, Chang PC, Yang JC, Chu CY, Wang LY, Chen NT et al. Autophagy blockade sensitizes prostate cancer cells towards Src family kinase inhibitors. Genes Cancer 2010; 1: $40-49$.

31. Tsai YT, Su YH, Fang SS, Huang TN, Qiu Y, Jou YS et al. Etk, a Btk family tyrosine kinase, mediates cellular transformation by linking Src to STAT3 activation. Mol Cell Biol 2000; 20: 2043-2054.

32. Wang XY, Wu MH, LiU F, Li Y, Li N, Li GY et al. Differential miRNA expression and their target genes between NGX6-positive and negative colon cancer cells. Mol Cell Biochem 2010; 345: 283-290.

33. Gattolliat $\mathrm{CH}$, Thomas L, Ciafrè SA, Meurice G, Le Teuff G, Job B et al. Expression of miR-487b and miR-410 encoded by $14 \mathrm{q} 32.31$ locus is a prognostic marker in neuroblastoma. Br J Cancer 2011; 105: 1352-1361.

34. Zhang S, Hao J, Xie F, Hu X, Liu C, Tong J et al. Downregulation of miR-132 by promoter methylation contributes to pancreatic cancer development. Carcinogenesis 2011; 32: 1183-1189.

35. Formosa A, Lena AM, Markert EK, Cortelli S, Miano R, Mauriello A et al. DNA methylation silences miR-132 in prostate cancer. Oncogene 2013; 32: 127-134.

36. Navarro A, Diaz T, Martinez A, Gaya A, Pons A, Gel B et al. Regulation of JAK2 by miR135a: prognostic impact in classic Hodgkin lymphoma. Blood 2009; 114: 2945-2951.

37. Wang WL, Chatterjee N, Chittur SV, Welsh J, Tenniswood MP. Effects of $1 \alpha, 25$ dihydroxyvitamin D3 and testosterone on miRNA and mRNA expression in LNCaP cells. Mol Cancer 2011; 10: 58.

38. Zhang Y, Liao JM, Zeng SX, Lu H. p53 downregulates Down syndrome-associated DYRK1A through miR-1246. EMBO Rep 2011; 12: 811-817.

39. Kim WK, Park M, Kim YK, Tae YK, Yang HK, Lee JM et al. MicroRNA-494 downregulates KIT and inhibits gastrointestinal stromal tumor cell proliferation. Clin Cancer Res 2011; 17: 7584-7594

40. Ghisi M, Corradin A, Basso K, Frasson C, Serafin V, Mukherjee S et al. Modulation of microRNA expression in human T-cell development: targeting of NOTCH3 by miR-150. Blood 2011; 117: 7053-7062.

41. Wang B, Li W, Guo K, Xiao Y, Wang Y, Fan J. miR-181b promotes hepatic stellate cells proliferation by targeting p27 and is elevated in the serum of cirrhosis patients. Biochem Biophys Res Commun 2012; 421: 4-8.

42. Hu H, Du L, Nagabayashi G, Seeger RC, Gatti RA. ATM is down-regulated by N-Myc-regulated microRNA-421. Proc Natl Acad Sci USA 2010; 107: 1506-1511.

43. Zhang Y, Gong W, Dai S, Huang G, Shen X, Gao M et al. Downregulation of human farnesoid $X$ receptor by miR-421 promotes proliferation and migration of hepatocellular carcinoma cells. Mol Cancer Res 2012; 10: 516-522.

44. Dai Y, Siemann DW. Constitutively active c-Met kinase in PC-3 cells is autocrineindependent and can be blocked by the Met kinase inhibitor BMS-777607. BMC Cancer 2012; 12: 1-98.

45. Xiong J, Du Q, Liang Z. Tumor-suppressive microRNA-22 inhibits the transcription of E-box-containing c-Myc target genes by silencing c-Myc binding protein. Oncogene 2010; 29: 4980-4988.

46. Lam KS, Salmon SE, Hersh EM, Hruby VJ, Kazmierski WM, Knapp RJ. A new type of synthetic peptide library for identifying ligand-binding activity. Nature 1991; 354: 82-84.

47. McDonald $\mathrm{OB}$, Chen WJ, Ellis B, Hoffman $\mathrm{C}$, Overton L, Rink $\mathrm{M}$ et al. A scintillation proximity assay for the Raf/MEK/ERK kinase cascade: high-throughput screening and identification of selective enzyme inhibitors. Anal Biochem 1999; 268: 318-329.

48. Wilhelm S, Carter C, Lynch M, Lowinger T, Dumas J, Smith RA et al. Discovery and development of sorafenib: a multikinase inhibitor for treating cancer. Nat Rev Drug Discov 2006; 5: 835-844.

49. Dai $B$, Chen $H$, Guo S, Yang $X$, Linn DE, Sun $F$ et al. Compensatory upregulation of tyrosine kinase Etk/BMX in response to androgen deprivation promotes castration-resistant growth of prostate cancer cells. Cancer Res 2010; 70: 5587-5596.

50. Bagheri-Yarmand R, Mandal M, Taludker AH, Wang RA, Vadlamudi RK, Kung HJ et al. Etk/Bmx tyrosine kinase activates Pak1 and regulates tumorigenicity of breast cancer cells. J Biol Chem 2001; 276: 29403-29409.

51. Hur W, Velentza A, Kim S, Flatauer L, Jiang X, Valente D et al. Clinical stage EGFR inhibitors irreversibly alkylate Bmx kinase. Bioorg Med Chem Lett 2008; 18: 5916-5919.

52. Campos S, Hamid O, Seiden MV, Oza A, Plante M, Potkul RK et al. Multicenter, randomized phase II trial of oral $\mathrm{Cl}-1033$ for previously treated advanced ovarian cancer. $J$ Clin Oncol 2005; 23: 5597-5604.

53. Yang JC, Bai L, Yap S, Gao AC, Kung HJ, Evans CP. Effect of the specific Src family kinase inhibitor saracatinib on osteolytic lesions using the PC-3 bone model. Mol Cancer Ther 2010; 9: 1629-1637. 
54. van Bokhoven A, Varella-Garcia M, Korch $\mathrm{C}$, Johannes WU, Smith EE, Miller HL et al. Molecular characterization of human prostate carcinoma cell lines. Prostate 2003; 57: 205-225.

55. Lou Q, Wu J, Lam KS. A protein kinase assay system for both acidic and basic peptides. Anal Biochem 1996; 235: 107-109

56. Grosdidier A, Zoete V, Michielin O, Swiss Dock. a protein-small molecule docking web service based on EADock DSS. Nucleic Acids Res 2011; 39: W270-W277.

57. Morris GM, Huey R, Lindstrom W, Sanner MF, Belew RK, Goodsell DS et al. AutoDock4 and AutoDockTools4: automated docking with selective receptor flexibility. J Comput Chem 2009; 30: 2785-2791.

58. Solis FJ, Wets RJB. Minimization by random search techniques. Math Oper Res 1981; 6 : 19-30.

59. Phillips JC, Braun R, Wang W, Gumbart J, Tajkhorshid E, Villa E et al. Scalable molecular dynamics with NAMD. J Comput Chem 2005; 26: 1781-1802.

60. Zoete V, Cuendet MA, Grosdidier A, Michielin O. SwissParam: a fast force field generation tool for small organic molecules. J Comput Chem 2011; 32: 2359-2368.
61. Grasso AW, Wen D, Miller CM, Rhim JS, Pretlow TG, Kung HJ. ErbB kinases and NDF signaling in human prostate cancer cells. Oncogene 1997; 15: 2705-2716.

(c) (1)(2) Cell Death and Disease is an open-access journal published by Nature Publishing Group. This work is licensed under a Creative Commons Attribution-NonCommercialShareAlike 3.0 Unported License. The images or other third party material in this article are included in the article's Creative Commons license, unless indicated otherwise in the credit line; if the material is not included under the Creative Commons license, users will need to obtain permission from the license holder to reproduce the material. To view a copy of this license, visit http://creativecommons.org/licenses/ by-nc-sa/3.0/

Supplementary Information accompanies this paper on Cell Death and Disease website (http://www.nature.com/cddis) 